\title{
Corpora Cavernos invasion vs. Corpus Spongiosum invasion in Penile Cancer: A systematic review and meta-analysis
}

\author{
Zaishang $\mathrm{Li}^{1,2,3^{*}}$, Xueying $\mathrm{Li}^{* *}$, Wayne Lam ${ }^{5}$, Yabing Cao ${ }^{6}$, Jiunhung Geng7,8,9, Antonio Augusto Ornellas ${ }^{10}$, \\ Fangjian Zhou ${ }^{11,12,13 凶}$ and Hui Han ${ }^{11,12,13 凶}$ \\ 1. Department of Urology, Shenzhen People's Hospital, The Second Clinic Medical College of Jinan University 518060, Shenzhen, Guangdong, P. R. China. \\ 2. Department of Urology, First Affiliated Hospital of Southern University of Science and Technology, 518060, Shenzhen, Guangdong, P. R. China. \\ 3. Department of Urology, Minimally Invasive Urology of Shenzhen research and Development Center of Medical Engineering and Technology, 518060, \\ Shenzhen, Guangdong, P. R. China. \\ 4. Department of Oncology, The Seventh Affiliated Hospital Sun Yat-sen University, 518107, Shenzhen, Guangdong, P. R. China. \\ 5. Division of Urology, Department of Surgery, Queen Mary's Hospital, The University of Hong Kong, 999077, Hong Kong SAR, P. R. China. \\ 6. Department of Oncology, Hospital Kiang Wu, 999078, Macao SAR, P. R. China. \\ 7. Department of Urology, Kaohsiung Municipal Hsiao-Kang Hospital, 000800, Kaohsiung, Taiwan. \\ 8. Department of Urology, Kaohsiung Medical University Hospital, 000800, Kaohsiung, Taiwan. \\ 9. Kaohsiung Medical University, Kaohsiung, T 000800, Taiwan. \\ 10. Department of Urology, Brazilian National Institute of Cancer, 20230-130, Rio de Janeiro, Brazil. \\ 11. Department of Urology, Sun Yat-sen University Cancer Center, 510060, Guangzhou, Guangdong, P. R. China. \\ 12. State Key Laboratory of Oncology in South China, 510060, Guangzhou, Guangdong, P. R. China. \\ 13. Collaborative Innovation Center of Cancer Medicine, 510060, Guangzhou, Guangdong, P. R. China. \\ *These authors contributed equally to this research.
}

$\square$ Corresponding authors: Hui Han, M.D., Ph.D., TEL: 86-020-87343862; FAX: 86-20-87343656; E-mail: hanhui@ sysucc.org.cn; Address: Department of Urology, Sun Yat-sen University Cancer Center, Guangzhou, 510060, Guangdong, P.R. China. Fangjian Zhou, M.D., Ph.D., TEL.: 86-20-87343656; Fax: 86-20-87343656; E-mail: zhoufj@sysucc.org.cn; Address: Department of Urology, Sun Yat-sen University Cancer Center, Guangzhou, 510060, Guangdong, P.R. China.

(1) The author(s). This is an open access article distributed under the terms of the Creative Commons Attribution License (https://creativecommons.org/licenses/by/4.0/). See http://ivyspring.com/terms for full terms and conditions.

Received: 2020.11.28; Accepted: 2021.01.05; Published: 2021.01.30

\begin{abstract}
Objective: Changes were made in the $8^{\text {th }}$ edition of the American Joint Committee on Cancer (AJCC) staging system according to cavernosum invasion for penile squamous cell carcinoma. This study aimed to determine the difference of prognostic validity between corpora cavernosa $(\mathrm{CC})$ invasion and corpus spongiosum (CS) invasion.

Methods: In this study, we searched PubMed, Cochrane CENTRAL, and Embase to select Englishlanguage articles until July 15, 2020. Pooled analyses of hazard ratios (HRs) and odds ratios (ORs) were performed.

Results: Eleven studies including 3692 cases were included in the final ananlysis ( 1431 cases with CC and 1360 cases with CS). According to the anatomical structure, the pooled results demonstrated that patients with CC invasion had a similar rate of LNM to those with CS invasion (OR 1.34, 95\% confidence interval $(\mathrm{Cl}) 0.97-1.86 ; P=0.076$ ). However, patients with $C \mathrm{C}$ invasion had a higher rate of lymph node metastasis (LNM) than those with CS invasion according to the $8^{\text {th }}$ edition tumor stage $(\mathrm{OR} 1.58,95 \% \mathrm{Cl}$ 1.14-2.21; $P<0.001)$. Regarding survival, patients with CS invasion obtained a significantly better cancerspecific survival (CSS) (HR, 0.67; $95 \% \mathrm{Cl}, 0.46-0.96 ; P=0.030$ ), but not in overall survival (OS) (HR: 1.30; $95 \% \mathrm{Cl}, 0.52-3.20 ; P=0.585)$ than those with $C \mathrm{C}$ invasion. No a significant publication bias was observed by Begg's and Egger's tests.

Conclusions: The systematic comparison suggests that patients with CS invasion had better CSS than those with CC invasion. CC invasion was associated with a high risk of LNM. The conclusions should be validated by large-scale studies.
\end{abstract}

Key words: penile cancer, prognosis, meta-analysis, lymph node metastasis, stage 


\section{Introduction}

The tumor stage of penile carcinoma is defined according to anatomy which has few changes [1-5]. In 2008, Lejet et al. defined tumor involvement of the spongious and/or cavernous bodies as T2 or T3 which provides good prognostic stratification with a significant difference in survival [6]. This classification has been proven to be a good way to distinguish the survival of penile patients in some studies and was accepted by the American Joint Committee on Cancer (AJCC) tumor-node-metastasis (TNM) staging system until 2018 [5].

According to the latest TNM staging of penile carcinoma, the invasion of the corpus cavernosa (CC) and corpus spongiosum (CS) were classified as T3 and T2. Because of the incidence rate of penile cancer, there are few clinical data to verify the superiority of the 8th edition staging system [7-9]. However, some studies confirmed that there is room for improvement in the 8th edition of $\mathrm{T}$ staging to predict the prognosis of patients more accurately [7-9].

A meta-analysis in 2019 showed that CC invasion and CS invasion were also significant predictors of inguinal lymph node metastasis (LNM) [10]. However, this study failed to distinguish different anatomies and repeated statistics in the methods, so the results need further research.

To verify the prognostic value of the latest $T$ stage, we performed a meta-analysis to explore the survival and LNM of CC invasion and CS invasion.

\section{Materials and methods}

\section{Literature-search strategy}

We searched the primary sources (PubMed, Embase, and the Cochrane Library) before July 2020. The following MeSH term was searched in [Title/Abstract]: penile cancer, penile tumor, penile neoplasm, penile squamous cell carcinoma, corpora cavernosa, corpora spongiosa, metastases, staging (eTable 1 in the Supplement).

\section{Inclusion and exclusion criteria}

The inclusion criteria used were as follows: 1) determined the precise pathologically confirmed stage; 2 ) discriminated CC invasion and CS invasion; 3) reported the results of prognosis or LNM; and 4) written in English. Larger publications were included in the case of overlapping patient data from the same institution. If CC invasion and CS invasion were taken as a whole, the study was excluded.

\section{Data extraction and quality of data assessment}

The reviewers (Zaishang $\mathrm{Li}$ and Xueying $\mathrm{Li}$ ) independently extracted and summarized the information using the PICOS (Population, Intervention, Comparator, Outcome, and Study design) principle. A consensus meeting including a senior author (Hui Han) will be held to resolve any disagreements. The following information was extracted: year of publication, first author, country, recruitment period, sample size, age, follow-up time and outcome of the study. The quality assessment was performed according to the Cochrane Collaboration handbook [11]. Any disagreements regarding the studies were resolved via discussion among all authors.

The quality of studies was assessed by the Newcastle-Ottawa Quality Assessment Scale. A score of 0-9 (allocated as stars), except randomized controlled trials.

\section{Statistical analysis}

The survival rate of the patients affected was expressed as the hazard ratio (HR), and the presence of LNM was expressed as the odds ratio (OR). Engauge software was used to calculate the necessary data when survival data were not directly reported. For the rare cancer, T4 (number: Hölters S:2 and Wang: 2) was grouped together with T3, and these studies were also included in the final analysis $[9,12]$. One study was excluded from the survival analysis due to the limited number of patients (only 41 patients) [13]. If I $<40 \%$, the fixed effects model was used; otherwise, the random-effects model was used. Stata version 12 (Stata Corp, College Station, TX, USA) and R 2.14.1 (http://www.r-proje ct.org) were used. Sensitivity analyses were performed for high-quality studies. Funnel plots were used to screen for potential publication bias. The significance level was set at $5 \%$ or a $P$-value $<0.05$.

\section{Results}

\section{Summary of analyzed studies}

Eleven studies incorporating 3692 cases met the final analysis criteria. The selection process is shown in Figure 1. Among these studies, LNM was investigated in 7 studies [8, 13-18], and survival was investigated in 4 studies $[6,7,9,12]$ (Table 1). Four studies classified LNM on the basis of the anatomical structure (CC invasion or CS invasion) [14-17], and 3 studies classified LNM on the basis of tumor stage (T2: tumor invading into CS or T3: tumor invading into CC) $[8,12,13]$. The evaluation of publication bias was performed by Funnel plots, Begg's test and Egger's test (Figure 2, eTable 1 in the Supplement). The results of the sensitivity analysis are shown in eTable 2 in the Supplement. 


\section{Association between LNM and cavernosum invasion in penile cancer patients}

There were significant differences in anatomical structure and tumor stage. According to the anatomical structure, there was a partial intersection between CS invasion and CC invasion. However, there was no intersection between $\mathrm{T} 2$ and $\mathrm{T} 3$ according to the $8^{\text {th }}$ edition tumor stage. The associations between LNM and cavernosum invasion are presented separately in Table 2.
The pooled results demonstrated that patients with CS invasion had a similar rate of LNM to those with CC invasion according to the anatomical structure (OR 1.34, 95\% CI 0.97-1.86; $P=0.076$, Figure $3 \mathrm{~A})$. The results show a growing trend towards LNM in patients with CS invasion according to the anatomical structure without statistical significance.

However, patients with CC invasion had a higher rate of LNM than those with CS invasion according to the $8^{\text {th }}$ edition tumor stage (OR 1.58, 95\% CI 1.14-2.21; $P<0.001$ ) (Figure 3B).

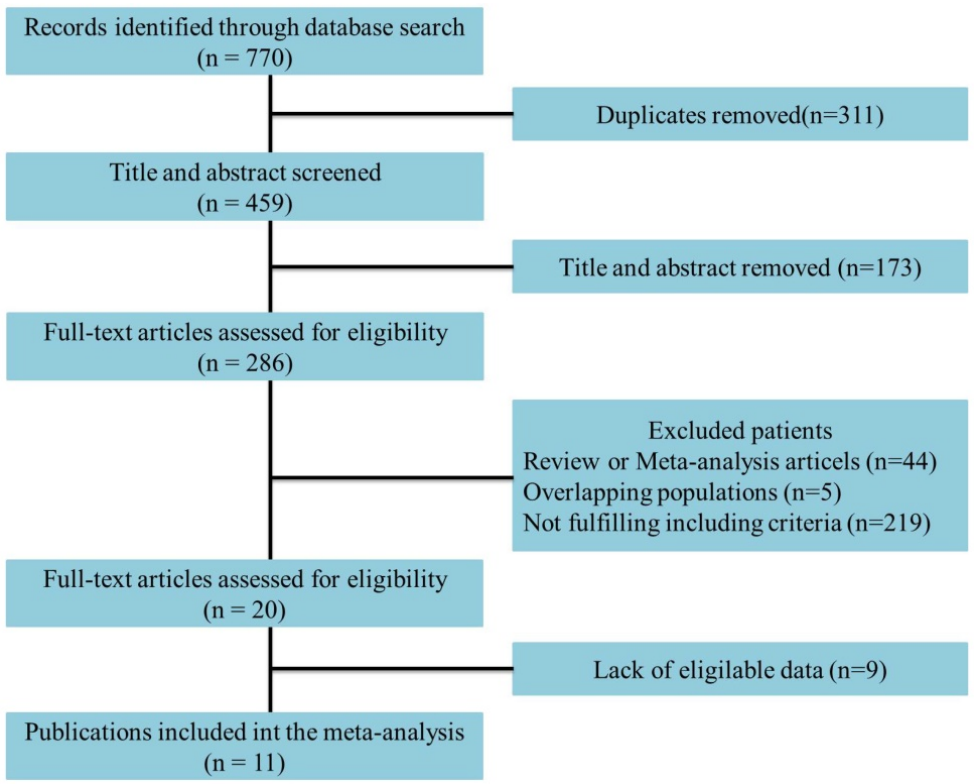

Figure 1. Flowchart of study selection.
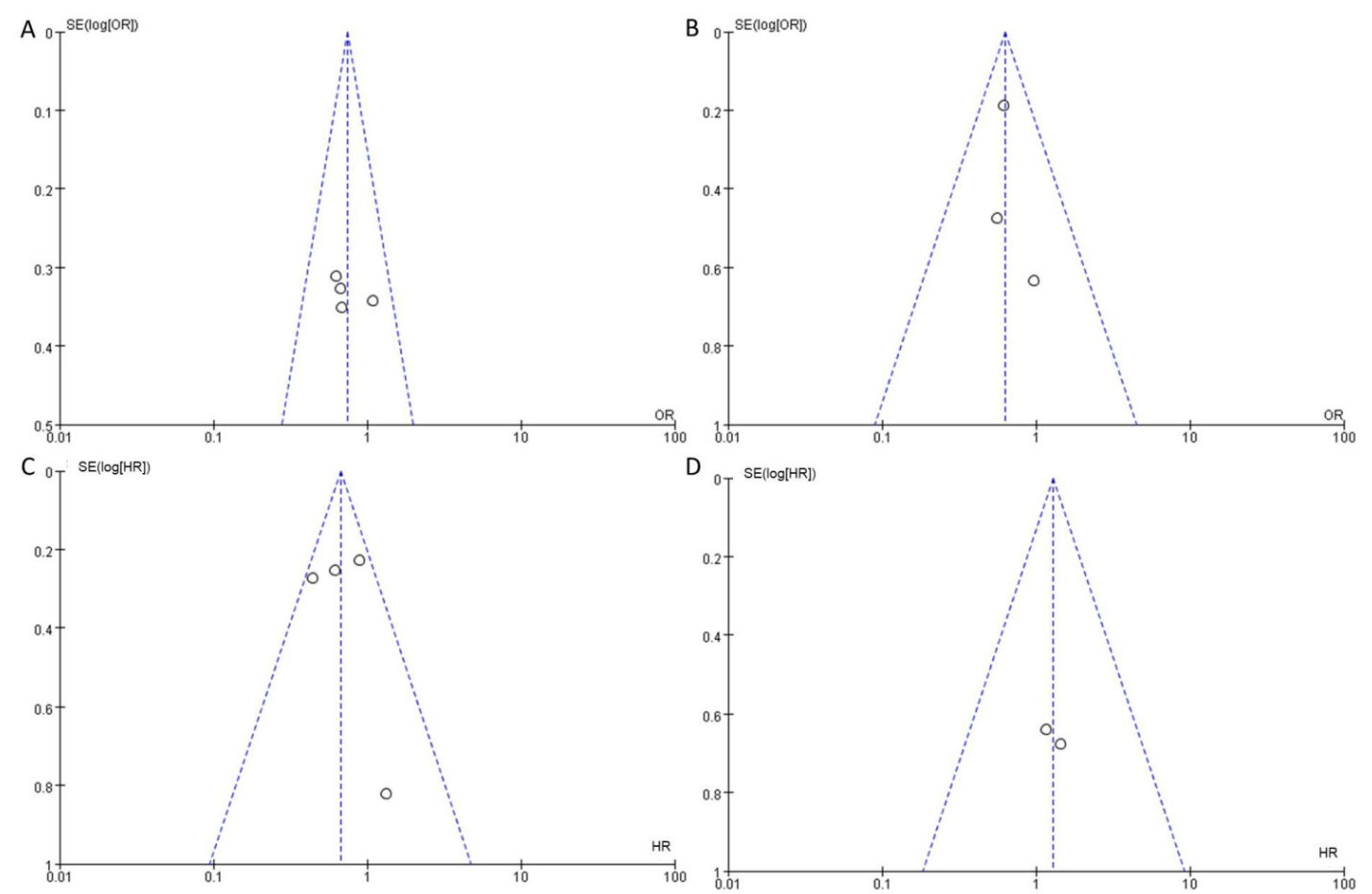

Figure 2. Funnel plots to detect the publication bias of eligible studies. A: according to the anatomical structure. B: according to the $8^{\text {th }}$ edition tumor stage. C: cancer-specific survival. D: overall survival. 
Table 1. Main characteristics of the studies

\begin{tabular}{|c|c|c|c|c|c|c|c|c|c|c|c|}
\hline Group & First author & Year & Country & $\begin{array}{l}\text { Recruitment } \\
\text { period }\end{array}$ & Number & $\begin{array}{l}\text { Age } \\
\text { (median) }\end{array}$ & $\begin{array}{l}\text { Follow-up } \\
\text { (mean/median) }\end{array}$ & $\begin{array}{l}\text { No. CC } \\
\text { invasion (\%) }\end{array}$ & $\begin{array}{l}\text { No. CS } \\
\text { invasion (\%) }\end{array}$ & $\begin{array}{l}\text { Outcomes } \\
\text { measured }\end{array}$ & $\begin{array}{l}\text { NOS } \\
\text { score }\end{array}$ \\
\hline \multirow[t]{4}{*}{ a } & Ficarra V & 2005 & Italy & $1980-2002$ & 175 & $62.0 \pm 12.2$ & $26(2-292)$ & $79(45.1)$ & $61(34.9)$ & LNM & 9 \\
\hline & Ornellas AA & 2008 & Brazil & 1996-2007 & 196 & $57(25-98)$ & $74(1-93)$ & $88(44.9)$ & $69(35.2)$ & LNM & 8 \\
\hline & Graafland NM & 2010 & Netherland & 2001-2008 & 342 & $65(26-96)$ & 31 (3-91) & $63(18.4)$ & $217(63.4)$ & LNM & 9 \\
\hline & Termini1 L & 2015 & Brazil & $1953-2000$ & 125 & NA & NA & $60(48.0)$ & $88(70.4)$ & LNM & 6 \\
\hline \multirow[t]{3}{*}{$b$} & Amr Al-Najar & 2011 & Germany & 1996-2008 & 89 & $31-91$ & $1-142$ & $18(20.2)$ & $23(25.8)$ & LNM & 8 \\
\hline & Kearns JT & 2019 & NCDB & 2010-2012 & 912 & NA & NA & $524(57.5)$ & $378(41.4)$ & LNM & 6 \\
\hline & Akash P. & 2020 & India & 2007- 2012 & 142 & NA & $21(1-96)$ & $45(31.7)$ & 97 (68.3) & LNM & 7 \\
\hline \multirow[t]{5}{*}{ c } & Leijte JA & 2008 & Netherland & $1956-2006$ & 513 & 65 (21-94) & $58.7(3-303)$ & $90(17.5)$ & $162(31.6)$ & Survival & 9 \\
\hline & Li ZS1 & 2018 & Global & 2000-2015 & 411 & $53(24-94)$ & $18(1-207)$ & $119(29.0)$ & $115(28.0)$ & Survival & 7 \\
\hline & $\mathrm{Li}^{2} \mathrm{~S}^{2}$ & 2018 & Global & 2000-2015 & 436 & 56 (18-93) & $35.4(1-349.7)$ & $142(32.6)$ & $142(32.6)$ & Survival & 7 \\
\hline & Hölters S & 2019 & Germany & 1992-2015 & 121 & $61.6(25-88)$ & $46.8(1-176)$ & $23(19.0)$ & $30(24.8)$ & Survival & 6 \\
\hline & Wang BH & 2020 & China & $1998-2015$ & 230 & $57(47-64)$ & $48.9(28.1-84.7)$ & $110(47.8)$ & $30(13.0)$ & Survival & 6 \\
\hline
\end{tabular}

a: LNM on the basis of the anatomical structure; b: LNM on the basis of tumor stage; c: survival on the basis of tumor stage. 1: training cohort; 2: external cohort; NCDB: National Cancer Database.

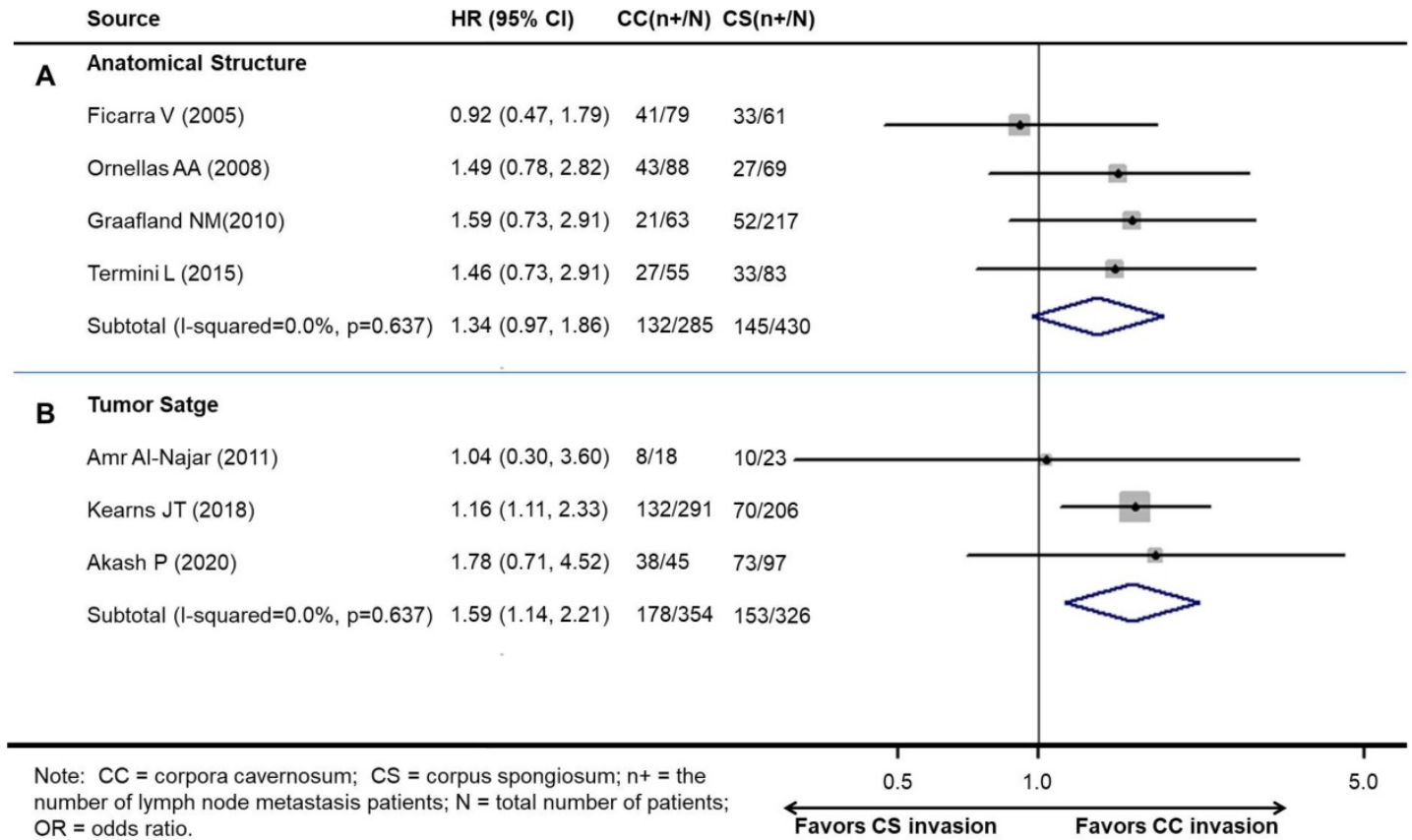

Figure 3. Meta-analysis of pooled odds ratios of association between LNM and cavernosum invasion in penile cancer. A: according to the anatomical structure. B: according to the $8^{\text {th }}$ edition tumor stage.

\section{Association between survival and cavernosum invasion in penile cancer patient}

Studies on survival analysis were allocated according to tumor stage. There was one study that contained two independent cohorts. Therefore, four cohorts reported the relationship between cavernosum invasion and cancer-specific survival (CSS), and two studies reported the relationship between cavernosum invasion and overall survival (OS).

Overall, patients with CS invasion obtained a significantly better CSS (HR, 0.67; 95\% CI, 0.46-0.96; $P=0.030$, Figure $4 \mathrm{~A}$ ), but not OS (HR: $1.30 ; 95 \% \mathrm{CI}$, 0.52-3.20; $P=0.585$ ) than $C C$ invasion (Figure 4B).

Preplanned subgroup analysis revealed the results of CC invasion compared with CC invasion (Table 3).

Table 2. Pooled nodal metastasis prevalence in penile cancer by stratification studies

\begin{tabular}{|c|c|c|c|c|c|}
\hline \multirow[t]{3}{*}{ Group } & \multirow[t]{3}{*}{ First author } & \multicolumn{2}{|c|}{ CC invasion $\mathrm{n}(\%)$} & \multicolumn{2}{|c|}{ CS invasion $\mathrm{n}(\%)$} \\
\hline & & Nodal & Nodal & Nodal & Nodal \\
\hline & & $\begin{array}{l}\text { Metastasis } \\
\text { (absent) }\end{array}$ & $\begin{array}{l}\text { Metastasis } \\
\text { (present) }\end{array}$ & $\begin{array}{l}\text { Metastasis } \\
\text { (absent) }\end{array}$ & $\begin{array}{l}\text { Metastasis } \\
\text { (present) }\end{array}$ \\
\hline \multirow[t]{4}{*}{ a } & Ficarra V & $38(48.1)$ & $41(51.9)$ & $28(45.9)$ & $33(54.1)$ \\
\hline & Ornellas AA & $45(51.4)$ & $43(48.7)$ & $42(60.9)$ & $27(39.1)$ \\
\hline & Graafland NM & $42(66.7)$ & $21(33.3)$ & $165(76.0)$ & $52(24.0)$ \\
\hline & Termini L & $28(50.9)$ & $27(49.1)$ & $50(60.2)$ & $33(39.8)$ \\
\hline \multirow[t]{3}{*}{$b$} & Amr Al-Najar & $10(55.6)$ & $8(44.4)$ & $13(56.5)$ & $10(43.5)$ \\
\hline & Kearns JT & $159(54.6)$ & $132(45.4)$ & $136(66.0)$ & $70(34.0)$ \\
\hline & Akash P. & $7(15.5)$ & $38(84.4)$ & $24(24.7)$ & $73(75.3)$ \\
\hline
\end{tabular}




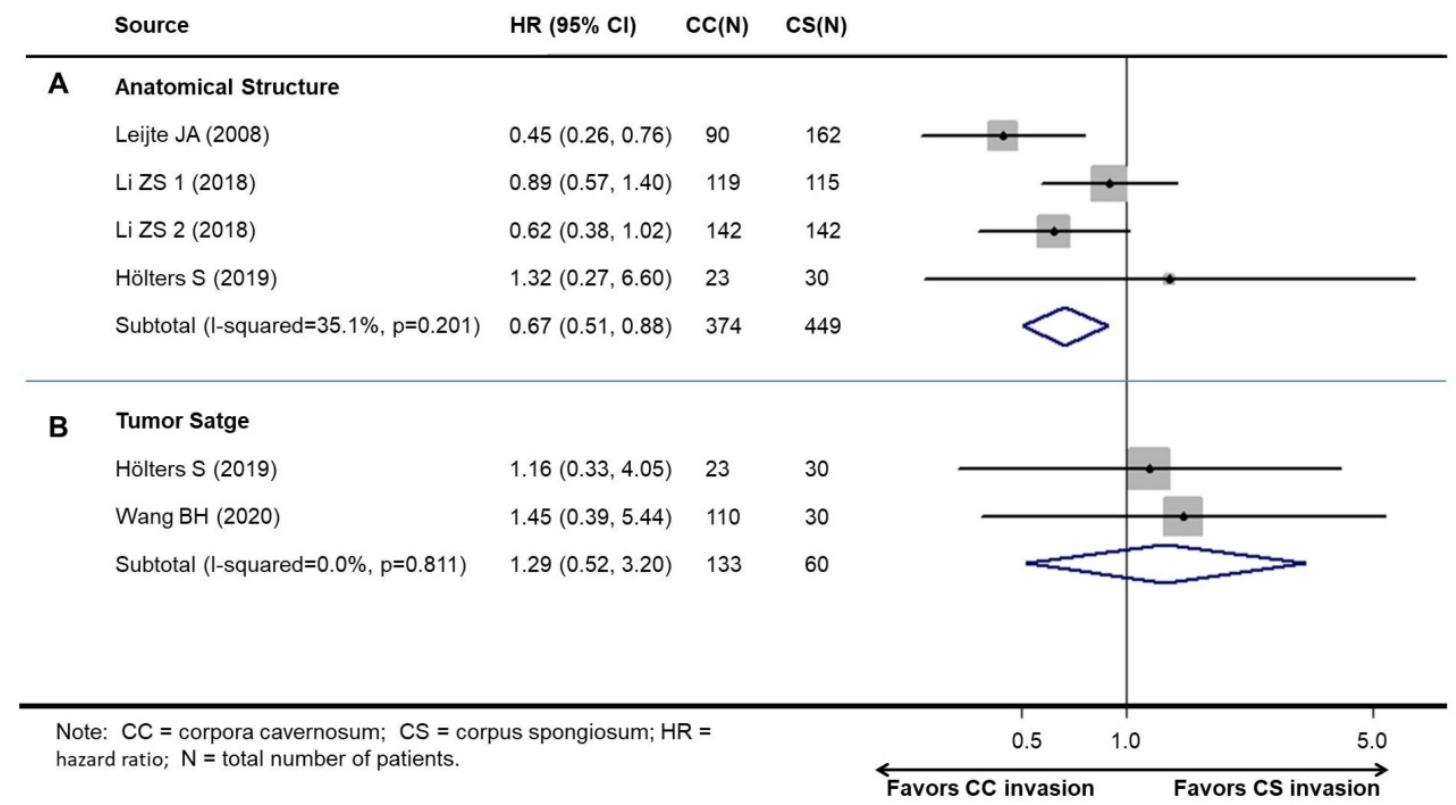

Figure 4. Meta-analysis of pooled hazard ratios of survival outcomes of cavernosum invasion in penile cancer patient. A: cancer-specific survival. B: overall survival.

Table 3. Main characteristics of the studies

\begin{tabular}{|c|c|c|c|c|c|c|}
\hline \multirow[t]{2}{*}{ Analysis } & \multirow{2}{*}{$\begin{array}{l}\text { No. of } \\
\text { studies }\end{array}$} & \multirow[t]{2}{*}{ HR/OR (95\% CI) } & \multirow[t]{2}{*}{ Model } & \multirow[t]{2}{*}{$P$ Value } & \multicolumn{2}{|c|}{ Heterogeneity } \\
\hline & & & & & I2 (\%) & $P$ Value \\
\hline \multicolumn{7}{|c|}{ Subgroup 1 (CSS): follow-up time } \\
\hline$<36$ months & 2 & $0.76(0.54-1.06)$ & Fixed & 0.104 & 13.4 & 0.283 \\
\hline$\geq 36$ months & 2 & $0.50(0.30-0.83)$ & Fixed & 0.007 & 37.2 & 0.207 \\
\hline \multicolumn{7}{|c|}{ Subgroup 2 (CSS): age } \\
\hline$<60$ & 2 & $0.50(0.30-0.83)$ & Fixed & 0.007 & 37.2 & 0.207 \\
\hline$\geq 60$ & 2 & $0.76(0.54-1.06)$ & Fixed & 0.104 & 13.4 & 0.283 \\
\hline \multicolumn{7}{|c|}{ Subgroup 3 (CSS): sample size } \\
\hline$\geq 400$ & 3 & $0.64(0.43-0.95)$ & Random & 0.028 & 48.8 & 0.142 \\
\hline
\end{tabular}

\section{Discussion}

This study is the first systematic review to assess the difference between CS invasion and CC invasion in penile cancer. This study confirmed that patients with CS invasion have significantly higher CSS rates. However, no significant difference was found for OS between them. Interestingly, patients with CC invasion had a higher rate of LNM than those with CS invasion according to the $8^{\text {th }}$ edition tumor stage (OR $1.58,95 \%$ CI 1.14-2.21; P<0.001). Simultaneously, there is a growing trend towards LNM in patients with CC invasion according to the anatomical structure (OR 1.34, 95\% CI 0.97-1.86; $P=0.076$ ). These results reflected that the $8^{\text {th }}$ edition AJCC staging system, especially the tumor stage, needs to be verified in the more clinical researches.

The $8^{\text {th }}$ edition AJCC staging system also has room for improvement to better predict prognosis [7, $8,12,19,20]$. In 2008, Leije et al found that patients with cavernosal involvement had a more aggressive histology with nodal involvement and worse survival [6]. Given these findings, they proposed a modified stage of spongiosal involvement or cavernosal involvement as different $\mathrm{pT}$ stages. Consistent with these findings, some studies have also found that spongiosal and cavernosal involvement have significant prognostic differences [18]. This classification was accepted by the AJCC TNM staging system until 2018. However, the $8^{\text {th }}$ edition AJCC staging system also has controversy [7, 8, 12]. To resolve disputes, we performed a meta-analysis to verify the prognostic value of the $8^{\text {th }}$ edition $T$ stage. The results suggested that patients with CS invasion obtained a significantly better CSS than those with CC invasion but not OS.

A meta-analysis showed that CC invasion and CS invasion were significant predictors of inguinal LNM [10]. This meta-analysis including one study reported that CC and CS infiltration combined were able to predict LNM. However, this meta-analysis failed to distinguish different anatomies (Figure 7 in $\mathrm{Hu} \mathrm{J}$ et. al. study), and subgroup analyses were only included one or two studies (Figure 4 in $\mathrm{Hu} \mathrm{J}$ et. al. study), so the results need further research. In our study, anatomical structure (CC invasion or CS invasion) and tumor stage (T2: tumor invading into CS or T3: tumor invading into CC) were calculated separately.

It is well established that clinicopathological features can predict LNM [21, 22]. Some studies have shown that CS invasion or CC invasion differs from nodal involvement [23]. Studies suggested that patients with CS invasion had a higher rate of LNM than those with CS invasion [6, 10, 16, 21-23]. Contrary to the above points, however, spongiosal 
and cavernosal involvement did not show a significant correlation with nodal metastasis $[8,13$, 16]. The risk-adapted stratification of the European Association of Urology (EAU), which included primary tumor stage and histologic grade, was recommended to estimate the incidence rate of LNM [21]. Solsona E et al. suggested that $83 \%$ of patients with pT2/3-G2/3 tumors had LNM; in contrast, pT1G1 tumors were not found to have LNM. However, occult nodal involvement will overestimate adherence to risk-adapted stratification, which would have led to $77 \%$ of patients not undergoing bilateral inguinal lymph node dissection (LND) [24].

There are some limitations to this study. 1) The number of studies was small. The analysis of OS included only two studies, which may not provide sufficient power to draw reliable conclusions. 2) The HRs were extracted from indirect comparisons. We used Engauge software to extract Kaplan-Meier curve data, which also contributed to heterogeneity. 3) Factors might impact survival, for example surgical treatments, adjuvant/or neoadjuvant therapy, nodal status, size of tumors, local vascular invasion or lymphatic invasion etc. Due to the limited number of included studies and lacked of article information, we did not perform subgroup analysis. 4) This study only involved the CSS and OS. Other outcomes will be important in future validation studies of larger and multicentre data sets. Considering these drawbacks, we firmly believe that the persuasive power of the results will greatly increase with further research.

\section{Conclusion}

In summary, patients with CS invasion had better CSS than those with CC invasion but not OS. Our data also show that patients with CC invasion are associated with a high risk of LNM. However, due to the limited number of included studies, a larger sample size is needed for validation, which may provide a useful guide for clinicians.

\section{Abbreviations}

AJCC: American Joint Committee on Cancer; CC: corpora cavernosa; CI: confidence interval; CS: corpus spongiosum; CSS: cancer-specific survival; HR: hazard ratio; LNM: lymph node metastasis; OR: odds ratio; OS: overall survival; TNM: tumor-nodemetastasis.

\section{Acknowledgements}

The authors wish to thank all the patients and their families.

\section{Funding}

This work was supported by the National
Natural Science Foundation of China (Grant No. 81772755, No. 81902610).

\section{Author contributions}

H. H. had full access to all the data in the study and takes responsibility for the integrity of the data and the accuracy of the data analysis.

- Study conception and design: ZS Li, XY Li, FJ Zhou and H Han;

- Acquisition of data: ZS Li, XY Li;

- Analysis and interpretation of data: ZS Li, XY Li, Wayne Lam, FJ Zhou and H Han;

- Drafting of the manuscript: ZS Li, XY Li and Wayne Lam;

- Critical revision of the manuscript for important intellectual content: PH Lin, JH Geng, AA Ornellas, FJ Zhou and H Han;

- Statistical analysis: ZS Li, XY Li, Wayne Lam, FJ Zhou and H Han;

- Obtaining funding: ZS Li and H Han;

- Administrative, technical, or material support: FJ Zhou and H Han;

- Supervision: FJ Zhou and H Han;

- Other (specify): None.

\section{Data availability statement}

The datasets used in the current study are available from the corresponding author upon reasonable request.

\section{Competing Interests}

The authors have declared that no competing interest exists.

\section{References}

1. $\mathrm{MH}$ H. TNM Classification of Malignant Tumors. Geneva: UICC. 1978

2. Hermanek P, Scheibe O, Spiessl B, Wagner G. [TNM classification of malignant tumors: the new 1987 edition]. Radiobiol Radiother (Berl). 1987; 28: $845-6$

3. SE. A. EAU penile cancer guidelines 2004. 2004

4. Edge SB. American Joint Committee on Cancer. AJCC cancer staging manual. 7th ed. New York: Springer. 2009.

5. Pettaway CA, John RS, KB. R. Penis. In: Amin MB, Edge SB, Greene FL, eds. AJCC Cancer Staging Manual. Chicago, IL: American College of Surgeons. 2018; p: 709-22.

6. Leijte JA, Gallee M, Antonini N, Horenblas S. Evaluation of current TNM classification of penile carcinoma. J Urol. 2008; 180: 933-8; discussion 8 .

7. Li ZS, Ornellas AA, Schwentner C, Li X, Chaux A, Netto G, et al. A modified clinicopathological tumor staging system for survival prediction of patients with penile cancer. Cancer Commun (Lond) 2018. 38. 68 .

8. Kearns JT, Winters BD, Holt SK, Mossanen M, Lin DW, Wright JL. Pathologic Nodal Involvement in Patients With Penile Cancer With Cavernosal Versus Spongiosal Involvement. Clin Genitourin Cancer. 2019; 17: e156-e61.

9. Wang B, Gu W, Wan F, Wei Y, Xiao W, Lu X, et al. Prognosis of the 8th TNM Staging System for Penile Cancer and Refinement of Prognostication by Incorporating High Risk Human Papillomavirus Status. J Urol. 2020; 203: $562-9$

10. Hu J, Cui Y, Liu P, Zhou X, Ren W, Chen J, et al. Predictors of inguinal lymph node metastasis in penile cancer patients: a meta-analysis of retrospective studies. Cancer Manag Res. 2019; 11: 6425-41.

11. JPT. H, S. G. Cochrane Collaboration. Cochrane Handbook for Systematic Reviews of Interventions (Version 5.1.0). The Cochrane Collaboration. . 2011. 
12. Holters $\mathrm{S}$, Khalmurzaev $\mathrm{O}$, Pryalukhin $\mathrm{A}$, Loertzer $\mathrm{P}$, Janssen $\mathrm{M}$, Heinzelbecker J, et al. Challenging the prognostic impact of the new WHO and TNM classifications with special emphasis on HPV status in penile carcinoma. Virchows Arch. 2019; 475: 211-21.

13. Al-Najar A, Alkatout I, Al-Sanabani S, Korda JB, Hegele A, Bolenz C, et al. External validation of the proposed $\mathrm{T}$ and $\mathrm{N}$ categories of squamous cell carcinoma of the penis. International journal of urology : official journal of the Japanese Urological Association. 2011; 18: 312-6.

14. Ficarra V, Zattoni F, Cunico SC, Galetti TP, Luciani L, Fandella A, et al. Lymphatic and vascular embolizations are independent predictive variables of inguinal lymph node involvement in patients with squamous cell carcinoma of the penis: Gruppo Uro-Oncologico del Nord Est (Northeast UroOncological Group) Penile Cancer data base data. Cancer. 2005; 103: 2507-16.

15. Ornellas AA, Nobrega BL, Wei Kin Chin E, Wisnescky A, da Silva PC, de Santos Schwindt AB. Prognostic factors in invasive squamous cell carcinoma of the penis: analysis of 196 patients treated at the Brazilian National Cancer Institute. J Urol. 2008; 180: 1354-9.

16. Graafland NM, Lam W, Leijte JA, Yap T, Gallee MP, Corbishley C, et al. Prognostic factors for occult inguinal lymph node involvement in penile carcinoma and assessment of the high-risk EAU subgroup: a two-institution analysis of 342 clinically node-negative patients. Eur Urol. 2010; 58: 742-7.

17. Termini L, Fregnani JH, Boccardo E, da Costa WH, Longatto-Filho A, Andreoli $\mathrm{MA}$, et al. SOD2 immunoexpression predicts lymph node metastasis in penile cancer. BMC Clin Pathol. 2015; 15: 3.

18. Sali AP, Menon S, Murthy V, Prakash G, Bakshi G, Joshi A, et al. A Modified Histopathologic Staging in Penile Squamous Cell Carcinoma Predicts Nodal Metastasis and Outcome Better Than the Current AJCC Staging. Am J Surg Pathol. 2020; 44: 1112-7.

19. Sanchez DF, Fernandez-Nestosa MJ, Canete-Portillo S, Cubilla AL. Evolving insights into penile cancer pathology and the eighth edition of the AJCC TNM staging system. Urol Oncol. 2020.

20. Khalil MI, Kamel MH, Dhillon J, Master V, Davis R, Hajiran AJ, et al. What you need to know: updates in penile cancer staging. World J Urol. 2020.

21. OW. H, EM. C, S. M, European Association of U. (2020)EAU Guidelines on Penile Cancer. 2020.

22. WF. T, ES. P, A. N. Penile Cancer, Version 2.2021, NCCN Clinical Practice Guidelines in Oncology. J Natl Compr Canc Netw. 2020.

23. Leijte JA, Horenblas S. Shortcomings of the current TNM classification for penile carcinoma: time for a change? World J Urol. 2009; 27: 151-4.

24. Solsona E, Iborra I, Rubio J, Casanova JL, Ricos JV, Calabuig C. Prospective validation of the association of local tumor stage and grade as a predictive factor for occult lymph node micrometastasis in patients with penile carcinoma and clinically negative inguinal lymph nodes. J Urol. 2001; 165 : 1506-9. 